\title{
Scanning electron microscopy as a confirmatory tool for morphological identification of Dirofilaria (Nochtiella) repens
} Original

Article

\author{
Safaa I Khedr'1, Doaa E Said ${ }^{1}$, Ibrahim M Zeitoun ${ }^{2}$, Nermine MFH Mogahed ${ }^{1}$ \\ Department of Medical Parasitology, Faculty of Medicine ${ }^{1}$, and Maxillofacial and Plastic \\ Surgery Department, Faculty of Dentistry², Alexandria University, Alexandria, Egypt
}

\begin{abstract}
Background: Dirofilaria repens (Railliet \& Henry, 1911) is a filarial nematode that mainly affects canids. It can also infect humans accidentally, causing subcutaneous or conjunctival lesions, especially in the OldWorld, including Egypt. Scanning electron microscopy (SEM) is very useful in diagnosis and identification of different parasites including $D$. repens.

Objectives: The current work aimed to use SEM as a confirmatory tool for morphological identification of D. repens.

Material and Methods: Morphological diagnosis of the excised nematodes was performed by studying their naked eye and light microscopic appearance. This was then confirmed using scanning electron microscopy (SEM).

Results: Three worms were identified; one was excised from a maxillofacial subcutaneous lesion and two were excised from a bulbar conjunctival lesion. All worms were females. Scanning electron microscopic examination showed external cuticular longitudinal ridges and circular striations on the worm surface especially in the mid-body region; which are characteristic for D. repens. The anterior end of the worms was wider than the posterior end that possessed a dimple-like anal orifice. The anterior end of the subconjunctival worms was spoon-like, and wider than that of the subcutaneous worm. The dimple-like anal orifice of the subconjunctival worm was more retracted than that of the subcutaneous worm.

Conclusion: SEM was used as a confirmatory tool for the diagnosis of two new human cases of dirofilariasis diagnosed in Egypt.
\end{abstract}

Keywords: arthropod-borne infections; Dirofilaria repens; filaria; subconjunctival lesions; subcutaneous lesions; zoonosis.

Received: 14 December, 2020, Accepted: 21 January, 2021.

Corresponding Author: Safaa I Khedr, Tel.: +20 1203831492, E-mail: Siak_1380@yahoo.com

Print ISSN: 1687-7942, Online ISSN: 2090-2646, Vol. 14, No. 1, April, 2021.

\section{INTRODUCTION}

Accidental human infection with dirofilarial nematodes can be considered as an emerging disease in many areas of the world ${ }^{[1]}$. There are about 40 recognized species of Dirofilaria. Only 6 species have been shown to accidentally infect humans as dead-end hosts. These are D. immitis, D. repens, $D$. tenuis, D. striata, D. ursi and D. spectans ${ }^{[2]}$. However, human cases in endemic areas in Europe especially Mediterranean region, Africa and southern eastern regions of $\mathrm{Asia}^{[3]}$, are mainly caused by two species; D. immitis and D. repens ${ }^{[3,4]}$. It is worth mentioning that D. immitis (Francesco Birago, 1626) belongs to the Dirofilaria subgenus and is mainly detected in the pulmonary artery, and the right ventricle of dogs and cats and rarely man, thus, causing the visceral or pulmonary form ${ }^{[3,4]}$. On the other hand, D. repens (Railliet \& Henry, 1911) belongs to the subgenus Nochtiella. It is mainly found in the subcutaneous tissue of canines and felines, and accidentally man, and is accordingly responsible for the subcutaneous and subconjunctival infections ${ }^{[3,4]}$.
Several factors have promoted the geographic range of dirofilariasis including global warming, increase in movement of the parasite animal reservoirs, and increased travelling frequency to endemic regions. Consequently, the risk of human infection has hightened as well. Although the medical awareness has substantially improved, D. repens is currently the most commonly filarial species reported as spreading from southern to northern Europe $^{[5,6]}$. Despite its worldwide increasing impact in both zoonotic and human fields, D. repens has often received less attention by scientists compared to $D$. immitis ${ }^{[4]}$. It was reported by a PubMed search (accessed on $1^{\text {st }}$ May 2018) that papers focused on $D$. repens are only $20 \%$ of the number of publications compared to that concerning D. immitis (i.e. 345 vs 1817). Consequently, many aspects of D. repens are still poorly understood ${ }^{[4]}$.

Adult worms of $D$. repens are usually less than 1 $\mathrm{mm}$ in diameter, females may reach up to $15 \mathrm{~cm}$ in length and males are usually about half this length ${ }^{[7]}$. The fertilized female releases microfilariae that 
circulate in its definitive host's blood, and become collected by the intermediate host female mosquitoes belonging to species of Anopheles, Culex and Aedes. Inside mosquitoes, microfilariae are transformed into the third stage larvae, that are infective to other definitive hosts ${ }^{[8]}$.

Thus, human can act as an accidental unnatural definitive host for $D$. repens, in whom the larva wanders causing a larva migrans syndrome without reaching maturity due to arrested development of the larvae ${ }^{[1]}$. Middle aged adults are the most commonly affected ${ }^{[9]}$, and the infections are usually asymptomatic ${ }^{[10]}$. However, sometimes, the wandering larva resides in the subcutaneous tissue, presenting as a painful subcutaneous nodule, causing variable symptoms depending on the target site, with greater prevalence in the upper body, mostly in the head, especially around the eyes ${ }^{[11-13]}$.

The importance of accidental human dirofilariasis repens is that the resulting subcutaneous lesions are commonly mistaken for sebaceous cysts, abscesses, or even malignant tumors, thus requiring invasive management ${ }^{[14]}$. Human infection was reported for the first time by Skrjabin in $1930^{[15]}$.

Being an African country and a part of the Mediterranean basin as well, Egypt has witnessed sporadic cases of D. repens since 1998, when Awadalla et $a l^{[16]}$ reported for the first time a case of eyelid dirofilariasis in Alexandria. Since then, more cases have been reported every now and then. Antonios and Bayoumy ${ }^{[17]}$ reported another case of human infection with D. repens in a 30 years-old female's neck from ElAmriya, Alexandria. Two years later, Maher et al. ${ }^{[18]}$ reported a single worm from an eyelid nodule in a 50 years-old female case from Cairo. Interestingly, from Assuit, Abd Elrahman et al. ${ }^{[19]}$ reported three cases of $D$. repens infection; one pulmonary and two subcutaneous. More recently and also from Alexandria, Elsayad et $a l^{[1]}$ reported two cases infected with $D$. repens worm in the subcutaneous tissue of the hand and anterior abdominal wall ${ }^{[1]}$. Since then, no cases were reported in Egypt to the best of our knowledge.

The current study aims to use the SEM as a confirmatory tool for diagnosis and comparison of the ultrastructure of $D$. repens worms extracted from different body lesions. Worms were excised from human maxillofacial subcutaneous mass and human bulbar conjunctiva.

\section{MATERIAL AND METHODS}

This descriptive study was conducted at Medical Parasitology Department, Faculty of Medicine, Alexandria University, in 2016. The study was conducted on three worms. One of them was excised from a subcutaneous maxillofacial mass, two worms were extracted from the bulbar conjunctiva.

Worms extracted from both lesions were washed thoroughly in buffered saline and their dimensions were measured. Parts of the mid-body of the worms were fixed in buffered formalin (10\%) for about $24 \mathrm{~h}$ and embedded in paraffin. Five $\mu \mathrm{m}$ sections were cut and mounted on glass slides. The sections were stained with Hematoxylin and Eosin ${ }^{[1,8]}$

Scanning electron microscopic study (SEM): The anterior and posterior ends and parts of the midbody of the worms were fixed in glutaraldehyde (3\%), buffered with $0.1 \mathrm{M}$ of sodium cacodylate ( $\mathrm{pH} 7.4)$, then dehydrated in acetone series, transferred to liquid $\mathrm{CO} 2$, and dried. Worm parts were then mounted on metal stubs, sputtered with gold, and examined using a LeitzAMR SEM $^{[1,20]}$ (Leitz, Germany).

The first worm was extracted from a 28 yearsold male patient from Edko, El Beheira Governorate, who came to the Maxillofacial and Plastic Surgery Department, Faculty of Dentistry, Alexandria University, complaining of a painless right cheek swelling that was noticed two months earlier. The patient stated that the lesion presented as a single painless subcutaneous nodule associated with overlying erythema. The lesion grew gradually near the point of an insect bite. He did not experience any cutaneous migratory lesions. The patient was given a broad-spectrum antibiotic course for two weeks with no response. Differential diagnosis included: chronic buccal space abscess related to multiple decayed teeth, or a minor salivary gland tumor. Panoramic X-ray of the mandible showed multiple decayed teeth. Fine needle aspiration cytology of the swelling was inconclusive. Excisional biopsy was done through an intra-oral approach by cutting through the buccal mucosa and dissection of the tissues reaching under the buccinator muscle. During cutting through the lesion, a white fibrillar motile thread popped out suggesting a worm-related lesion.

The other two worms were extracted from a 43 years-old male patient from Abu Hummus, El Beheira Governorate, attending the Ophthalmology Department, Faculty of Medicine, Alexandria University. The patient complained of unilateral eye itching and rubbing, foreign body sensation, pain, excessive lacrimation, conjunctival congestion, edema, hyperemia and redness. Slit-lamp examination revealed thin whitish worms under the conjunctiva of the left eye. When an incision was made in the subconjunctival space, two worms were extracted. In both cases the in toto extracted worms were delivered to the Medical Parasitology Department, Faculty of Medicine, Alexandria University in 70\% alcohol for diagnosis.

On questioning, both patients declared that they inhabited mosquitoes' heavily infested areas, and 
both recalled numerous mosquito bites. Besides, the $1^{\text {st }}$ patient declared that there were a lot of stray dogs in the neighborhood of his habitat, while the $2^{\text {nd }}$ stated that he used to raise a guard dog in his home. The $1^{\text {st }}$ patient stated that he lived near a fish lake and the $2^{\text {nd }}$ patient declared that he lived near rice fields; both are rural habitats.

Blood samples were obtained from both patients to perform thick blood films. These were examined microscopically to detect microfilariae using Giemsa stain. Moreover, complete blood picture was performed for both patients to check for eosinophilia.

Ethical approval and informed consent: This study was performed in accordance with the Declaration of Helsinki and approved by the ethics committee of the Faculty of Medicine, Alexandria University. Informed consents were sought from both patients. Excised worms were forwarded by both, the maxillofacial surgeon and the ophthalmologist after their surgical removal.

\section{RESULTS}

Grossly, the excised tissue from the $1^{\text {st }}$ patient was greyish pink in color with granular surface and contained only one cylindrical worm. It measured about $13 \mathrm{~cm}$ in length and about $470 \mu \mathrm{m}$ in its largest diameter (Fig. 1a). On the other hand, two worms were extracted from the $2^{\text {nd }}$ patient. Morphologically, the worms measured 11.25 and $10.75 \mathrm{~cm}$ (in length) and about 340 and $310 \mu \mathrm{m}$ in their largest diameters (Fig. 1b). The worms were thin, cylindrical, and ivory white.

Histopathological examination of the worms presented in figures 2 and 3, revealed outer longitudinal ridges and circular striations, and a thick, multilayered cuticle that was especially expanding in the region of the two lateral chords. Beneath the cuticle, was a thick muscle layer comprised of tall coelomyarian muscle cells. According to Gardiner and Poynton ${ }^{[21]}$, the previously mentioned criteria are indicative for $D$. repens. Internally, a pseudocoelum was seen inside the bodies of the three worms. The worm extracted from the cheek lesion was a female with a digestive tract and a paired uterus without microfilariae (may be because the female is immature, pre-adult or unfertilized). Regarding the two worms extracted from the bulbar conjunctiva, because of their necrotic state (Fig. 3), it was not possible to assure their sex, but one of them showed a single reproductive tube. However, their length and the shape of their posterior ends suggested the female sex ${ }^{[21]}$ of an immature (preadult) worm.

The SEM study was conducted as a confirmatory diagnostic tool, according to Wong and Brummer ${ }^{[22]}$ who suggested that SEM is a useful tool for the detailed study of specific cuticular morphology of all Dirofilaria species, thus contributing toward better characterization, differentiation and recognition. The whole worm surface especially in the mid-body region showed circular striations and prominent longitudinal ridges each of which was separated by a distance that was wider than the width of the actual ridge itself (Figs. $4 \mathrm{c}, \mathrm{d}$ and $5 \mathrm{~d}, \mathrm{e}, \mathrm{f}$ ). The anterior end of the worm (Figs. $4 \mathrm{e}, \mathrm{f}$ and $5 \mathrm{f}, \mathrm{g}, \mathrm{h}$ ) was wider than the posterior end (Figs. $4 \mathrm{a}, \mathrm{b}$ and $5 \mathrm{a}, \mathrm{b}, \mathrm{c}$ ). While the posterior end was blunt and rounded, with a dimple like anal orifice in both cases (Figs. 4 a, b and 5 a, b, c). All of the afore mentioned descriptions are criteria of Dirofilaria of the subgenus Nochtiella ${ }^{[22]}$.

Interestingly, it was noted that the anterior end of the subconjunctival worms was obviously spoonlike, flatter, and wider (Fig. $5 \mathrm{f}, \mathrm{g}, \mathrm{h}$ ) than that of the subcutaneous worm with a groove on its posterior surface (Fig. 4 e, f). Yet, the dimple-like anal orifice in the posterior end in case of the subconjunctival worm was more retracted than in case of the worm extracted from the cheek (Figs. 4 a, b and 5 a, b, c).

Blood films of both patients were free from microfilariae. The patient complaining of maxillofacial dirofilariasis showed eosinophilic count (EC) of 427 from a total leucocytic count (TLC) of 4500 which is equivalent to $9.5 \%$. While the 2 nd patient showed EC of 420 from a TLC of 7000 which is equivalent to $6 \%$ despite the presence of two worms in the lesion. Eosinophilia disappeared after the extraction of the worms in both patients.

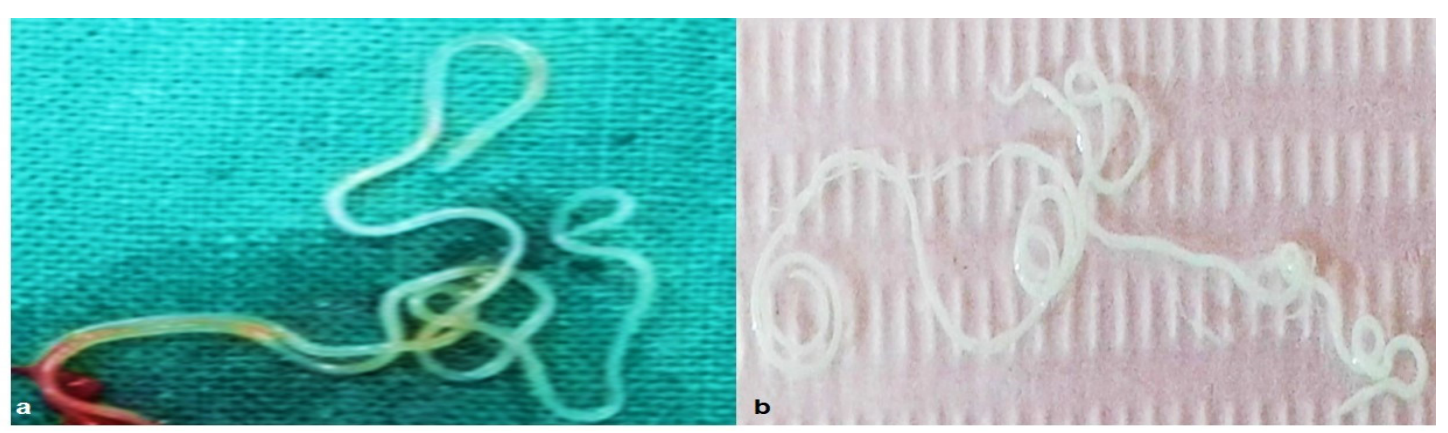

Fig. 1. Gross pictures of the excised worms. a: The excised worm from the maxillofacial lesion was thin, cylindrical, whitish $D$. repens worm measuring about $13 \mathrm{~cm}$. The anterior end was rounded while the posterior one was blunt and tapering. b: Two D. repens worms excised from the bulbar conjunctiva, were cylindrical, ivory white measuring about 11.25 and $10.75 \mathrm{~cm}$ in length. 


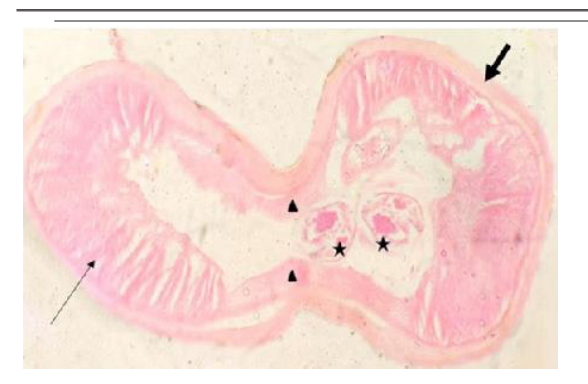

Fig. 2. Hematoxylin and eosin stained histopathological section of the female worm extracted from the subcutaneous lesion in the cheek, measuring about $470 \mu \mathrm{m}$ in its largest diameter (X400). The thick arrow points to the thick multi-layered cuticle. The thin arrow points to tall well-developed coelomyarian muscle layer. The two triangles point to the region of the two lateral chords. The two stars overlay the paired uterus.

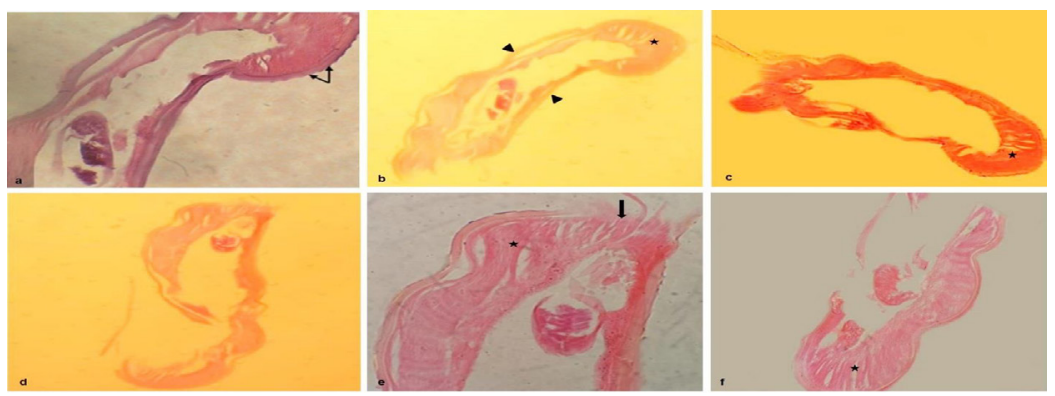

Fig. 3. Hematoxylin and eosin stained histopathological sections of the two worms extracted from the bulbar conjunctiva $(\times 400)$. (a-f): The thin arrow points to the outer longitudinal ridges. The stars overlay the tall well-developed coelomyarian muscle layer. The two triangles point to the region of the two lateral chords. The thick arrow points to the necrosed areas in the thick cuticle.
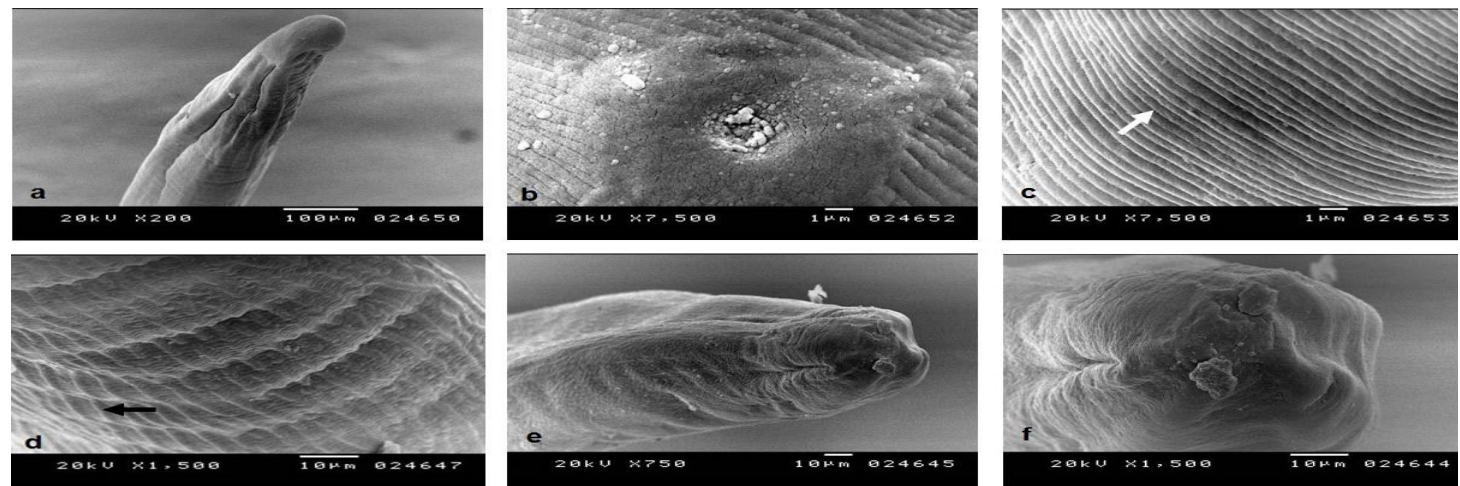

Fig. 4. Ultrastructural morphology (SEM) of the worm extracted from the subcutaneous lesion. a-b: The posterior end is blunt rounded with a dimple-like annual orifice. c-d: The worm surface showed both circular striations (white arrow) and longitudinal ridges (black arrow) over the whole worm especially in the mid-body region. e-f: The anterior end of the worm is wider than the posterior end.
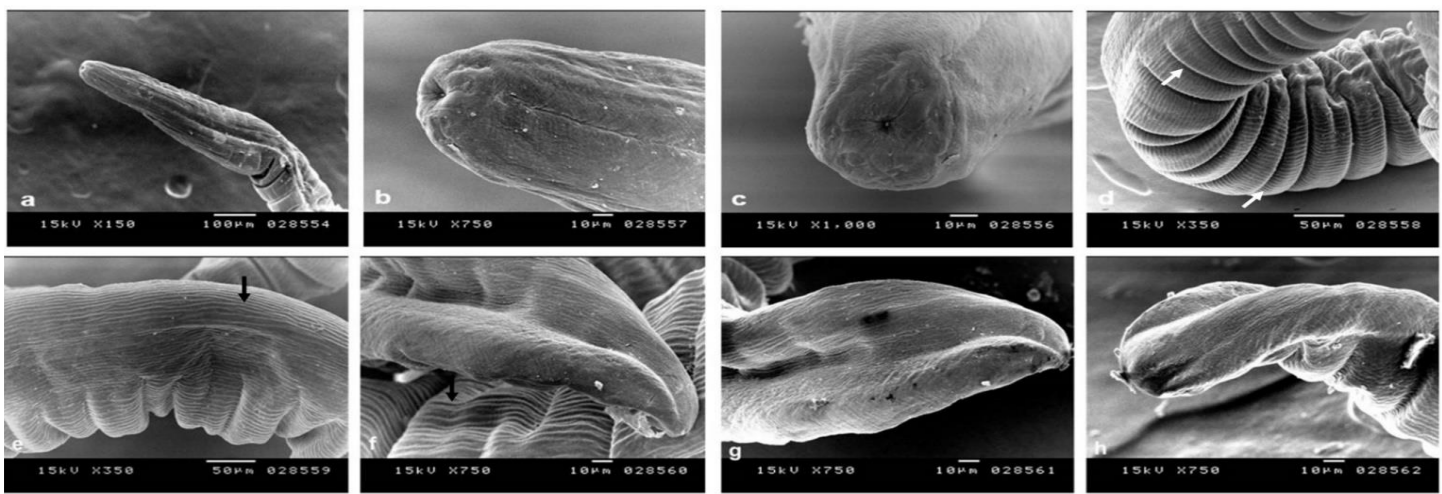

Fig. 5. Ultrastructural morphology (SEM) of the worm extracted from the bulbar conjunctiva. a-c: The posterior end is blunt rounded with a retracted dimple-like anal orifice. d-f: The worm epicuticle showed both longitudinal ridges (black arrows) and circular striations (white arrows) over the whole worm especially in the mid-body region. $\mathbf{f}-\mathbf{h}$ : The anterior end of the worm is spoon-like with a groove on its posterior surface. 


\section{DISCUSSION}

Amongst mosquito-transmitted nematodes with zoonotic potential especially in domestic and wild canids, Dirofilaria is becoming increasingly recognized worldwide as an accidental human pathogen. Dirofilariasis has shown an increased level of endemicity, throughout the past few decades, in many Old-World countries, especially around the Mediterranean basin, with predominance in warmer climatic zones ${ }^{[3,4]}$. Egypt belongs to the Old-World, to the Mediterranean basin, and to the warm climatic zones of the Ethiopian zoogeographical region which explains recurrent reporting of human cases since $1998^{[16]}$. It was very interesting for the current work authors to find new cases of D. repens in Egypt. Authors tried to confirm their diagnosis using SEM.

Using SEM, the worms extracted in our study showed longitudinal ridges and circular striations on their cuticle with abundant somatic musculature that were detected through histopathological examination ${ }^{[23]}$. The external longitudinal ridges of the cuticle are the feature that readily differentiates $D$. repens from $D$. immitis ${ }^{[24]}$.

The worms extracted from the conjunctival lesion showed varying degrees of disintegration. Some areas of the worm showed more degeneration than others, namely the myoid fibers, lateral chords. Apparently at this stage the walls of the digestive tract, and sexual tubules, were not yet necrosed ${ }^{[8,14]}$. However, it was not possible to ascertain the worms' sex because of their necrotic condition. According to Pampiglione et al. ${ }^{[8]}$ and Orihel et $a l^{[25]}$, the male worm sexual tubule is single, while the female vaginal tubules are multiple and grow and curl with the maturity of the worm. It was mentioned that if the morphology of the extracted worm is perfectly preserved, it means that the nematode was alive at the moment of removal ${ }^{[8]}$. This was noted in the worm extracted from maxillofacial lesion in the current work.

Although Pampiglione et al. ${ }^{[8]}$ stated that the differences noted between $D$. repens worms extracted from the subcutaneous tissue and those from the subconjunctival space were nil, nevertheless, in the current study, major differences were noted in the worms' anterior ends and slight differences were noted in the posterior ends.

Similarly, the use of SEM proved to be very beneficial in verifying the ultrastructure of different parasitic stages. Just to name a few; the type of the cuticular bosses in L. loa were identified using SEM as a key characteristic to distinguish Loa species from other Dirofilariinae genera ${ }^{[22,26]}$. Moreover, different species of the eye worms (Thelazia) (Spirurida, Thelaziidae) were identified using SEM ${ }^{[27]}$. Even in case of $W$. bancrofti in which viable adults are difficultly obtained from human tissues, SEM showed transversely striated cuticle with annulations and small protuberances that are irregularly distributed along the worm length ${ }^{[28]}$. Additionally, the role of SEM is not only limited to diagnosis of adult parasites. It also described and diagnosed larval stages of parasites, as D. immitis ${ }^{[29]}$, W. bancrofti ${ }^{[30]}, L_{\text {. }}$ loa $^{[31]}$ and recently M. ozzardi ${ }^{[32]}$.

In the current work, the one worm extracted from the cheek of the $1^{\text {st }}$ patient was in good shape and easily described. The two worms extracted from the conjunctiva were somewhat necrotic, which may be explained by the effect of the immune system stimulation although the eosinophilia was within normal $(6 \%)^{[11]}$ or by the crowding in a limited space. The eosinophilic count of $6 \%$ may be explained by the necrotic condition of the detected worms ${ }^{[33]}$. Noteworthy, it was found that conjunctival dirofilarial infection in the United States in particular is usually caused by $D$. tenuis, a parasite of raccoons, whereas in other areas of the world these infections are commonly caused by D. repens ${ }^{[34]}$.

In human dirofilariasis repens, mature adults are rarely developed, however, fertilized worms releasing microfilariae have been described in immunosuppressed patients ${ }^{[11]}$. This was not the case in the present work. It is known that subcutaneous migration of developing stages takes from weeks to months, usually unrecognized, except for some itching ${ }^{[11]}$; this explains the itching complained by both patients over the few months preceding their seeking for medical advice. After this migration, the worm stops at some site in the human body forming a small nodule. It was hypothesized that the subcutaneous localization of $D$. repens may help it to escape the natural immune response of their unusual human hosts ${ }^{[4]}$. In infection by $D$. immitis the immunogenic stimulation of specific antibodies is more vigorous than in case of $D$. repens infection. These specific antibodies block the activity of $D$. immitis enzymes and limits the capacity for survival of infective larvae in human patients ${ }^{[35]}$. Owing to the rarity of cases, the diagnosis of dirofilariasis is easy to miss throughout the world, especially in the Western Hemisphere. Furthermore, in contrary to D. immitis for which several sensitive and specific serological tests are available, no serologic test is available for $D$. repens. This makes the diagnosis of occult infections nearly impossible ${ }^{[36]}$. According to Haim et al. ${ }^{[37]}$, subcutaneous dirofilariasis lesions are mostly single and migratory lesions are not common because parasites are contained by the surrounding host immune response.

The predilection of the $D$. repens human lesions to the upper body especially in the head may be attributed to the available sites for biting by the vector mosquitoes ${ }^{[7,8,13]}$. An interesting exception is found in 
Sri Lanka, where most children cases are localized to male genital organs, and perineal regions of the body; attributed to the custom of allowing male toddlers to wear only upper garments ${ }^{[9]}$.

As expected, blood films of patients in the current work were negative for microfilariae, since the extracted female worms were sexually immature ${ }^{[38]}$ and non-fertilized due to absence of mating by male worms $^{[39,40]}$. A third explanation for this amicrofilaremia is that it may be due to the death of the majority of larvae released by the arthropod vector into the human body and the ones which grow usually cannot reach maturity ${ }^{[39,40]}$. To the best of our knowledge, there is only one medical report of circulating microfilariae in a case of human dirofilariasis ${ }^{[15]}$.

The residential history of the patients in the current study was mostly rural rather than urban. A previous report stated that residents of rural areas are four times more affected than town-dwellers ${ }^{[8]}$. This was actually the case in the current study, where the patients originated from Edko and Abou-Hummus. Prevalence in rural areas may be attributed to the effective insecticide treatment that is carried out in cities but is rendered less effective by the agricultural activities in the country side. Rice fields and irrigation activities result in formation of stagnant pools thus encouraging breeding of mosquito vectors ${ }^{[8]}$

The frequently asymptomatic subclinical or nonspecific nature of canine $D$. repens infections in the reservoir microfilaremic host together with the lack of clinical diagnosis contribute to its silent spread through canine reservoirs, thus, increasing the risk of infection in humans residing in the same areas ${ }^{[41]}$. This is confirmed by the patients' statements in the current work concerning the abundance of nearby stray dogs or raising of a pet dog, from which mosquitoes may have transmitted the disease. Although two cases are a relatively rare occurrence to raise an alarm, the danger that this zoonotic disease could become a human health problem in the affected region and nearby areas still exists.

Conclusion and recommendations: SEM was used as a confirmatory tool in the diagnosis of two new cases of $D$. repens in Egypt. Due to the subclinical nature of dirofilariasis repens, the deficient knowledge and poor awareness concerning the disease in non-endemicareas, health education concerning the way of acquisition of the disease and its clinical forms should improve, especially among dog owners. Besides, new diagnostic tools should be innovated to fill this gap and to refute the concept that human dirofilariasis is infrequent and accidental. Both, screening of dogs imported from the endemic areas and notification about new human cases are highly recommended. Physicians and veterinarians should collaborate for better surveillance of $D$. repens infection in humans and animals.
Authors contribution: Khedr S and Mogahed N designed the study, identified the worms, performed the electron microscopic examination, analyzed the data, wrote and revised the manuscript. El-Said D conceived and conceptualized the study. Zeitoun I provided the worms.

Conflict of interest statement: The authors declare that they have no conflict of interest.

Funding statement: This research did not receive any specific grant from funding agencies in the public, commercial, or not-for-profit sectors.

\section{REFERENCES}

1. Elsayad MH, Tolba MM, Yehia MAH, Ahmed SA, AbouHolw SA. Human subcutaneous dirofilariasis: report of two cases of Dirofilaria repens in Alexandria, Egypt. PUJ 2012; 5(1):67-72.

2. Horst A. Dirofilaria and dirofilarioses; Introductory remarks; Proceedings of Helminthological Colloquium. Vienna; 2003.

3. Genchi C, Kramer LH. The prevalence of Dirofilaria immitis and D. repens in the Old World (Review). Vet Para 2020; 280:108995.

4. Capelli G, Genchi C, Baneth G, Bourdeau P, Brianti E, Cardoso L, et al. Recent advances on Dirofilaria repens in dogs and humans in Europe. Parasit Vectors 2018; 11(1):663.

5. Petrić D, Zgomba M, Bellini R, Becker N. Surveillance of mosquito populations: A key element to understanding the spread of invasive vector species and vectorborne diseases in Europe. Mihailović D, ed. Essays on Fundamental and Applied Environmental Topics. Hauppauge, NY: Nova Science Publishers; 2012; 192224.

6. Sassnau R, Genchi C. Qualitative risk assessment for the endemisation of Dirofilaria repens in the state of Brandenburg (Germany) based on temperaturedependent vector competence. Parasitol Res 2013; 112(7):2647-2652.

7. Azari-Hamidian S, Yaghoobi-Ershadi MR, Javadian E, Abai MR, Mobedi I, Linton YM, et al. Distribution and ecology of mosquitoes in a focus of dirofilariasis in northwestern Iran, with the first finding of filarial larvae in naturally infected local mosquitoes. Med Vet Entomol 2009; 23: 111-121.

8. Pampiglione S, Rivasi F, Angeli G, Boldorini R, Incensati RM, Pastormerlo M, et al. Dirofilariasis due to Dirofilaria repens in Italy, an emergent zoonosis: report of 60 new cases. Histopathology 2001; 38(4): 344-354.

9. Dissanaike AS, Abeyewickreme W, Wijesundera MD, Weerasooriya MV, Ismail MM. Human dirofilariasis caused by Dirofilaria (Nochtiella) repens in Sri Lanka. Parassitologia 1997; 39(4):375-382.

10. Popescu I, Tudose I, Racz P, Muntau B, Giurcaneanu C, PoppertS. Human Dirofilaria repens infection in Romania: A Case Report. Case Rep Infec Dis 2012:472976.

11. Pampiglione S, Rivasi F. Human dirofilariasis due to Dirofilaria (Nochtiella) repens: an update of world 
literature from 1995 to 2000. Parassitologia 2000; 42(34):231-254.

12. Di Cesare A, Otranto D, Di Giulio E, Simonato G, Latrofa MS, La Torreet $F$, et al. Microfilarial periodicity of Dirofilaria repens in naturally infested dogs. Parasitol Res 2013; 112:4273-4279.

13. Sałamatin RV, Pavlikovska TM, Sagach OS, Nikolayenko $\mathrm{SM}$, Kornyushin VV, Kharchenko VO, et al. Human dirofilariasis due to Dirofilaria repens in Ukraine, an emergent zoonosis: epidemiological report of 1465 cases. Acta Parasitol 2013; 58: 592-598.

14. Pampiglione S, Rivasi F, Gustinelli A. Dirofilarial human cases in the Old World, attributed to Dirofilaria immitis: a critical analysis. Histopathology 2009; 54(2):192-204.

15. Skrjabin KI. Premier cas de Dirofilaria repens chez l'homme. Trop Med Vet 1930; 2:9.

16. Awadalla HN, Bayoumi DM, Ibrahim IR. The first case report of suspected human dirofilariasis in the eyelid of a patient from Alexandria. J Egypt Soc Parasitol 1998; 28:941-943

17. Antonios SN, Bayoumy SL. A case report of human dirofilariasis in Egypt. J Egypt Soc Parasitol 2002; 32: 355-356.

18. Maher M, El-Dib N, Zakaria E. Dirofilaria conjunctivae in eyelid nodule. In: Kamel R, Lumeley J. Textbook of Tropical Surgery, $1^{\text {st }}$ ed, 2004, Westminister Publishing Limited: 1267-1268.

19. Abdel-Rahman SM, Mahmoud AE, Galal LA, Gustinelli A, Pampiglione $S$. Three new cases of human infection with Dirofilaria repens, one pulmonary and two subcutaneous, in the Egyptian governorate of Assiut. Ann Trop Med Parasitol 2008; 102(6): 499-507.

20. Andersen T. Technique for preservation of threedimensional structures in preparing specimens for electron microscope. Academy Science; 1951, 13(4): 130-134.

21. Gardiner CH, Poynton SL. An Atlas of Metazoan Parasites in Animal Tissues. Washington, DC: Armed Forces Institute of Pathology, American Registry of Pathology; 1999.

22. Wong MM, Brummer ME. Cuticular morphology of five species of Dirofilaria: a scanning electron microscope study. J Parasitol 1978; 64(1):108-114.

23. Bhat KS, Kotigadde S, Vishwanatha Bhat K, Pare P. Subconjunctival dirofilariasis: Case studies with review of literature. Trop Parasitol 2014; 4(2):119-121.

24. Sathyan P, Manikandan P, Bhaskar M, Padma S, Singh G, Appalaraju B. Subcutaneous infection by Dirofilaria repens. Indian J Med Microbiol 2006; 24 (1):61-62.

25. Orihel TC, Helentjaris D, Alger J. Subcutaneous dirofilariasis: single inoculum, multiple worms. Am J Trop Med Hyg1997; 56(4):452-455.

26. Juul J A, Forsaa VA, Utheim TP, Willassen E. Scanning electron microscopy observations of Loa loa (Nematoda). Case Rep Ophthalmol 2020; 11:486-492.
27. Naem S. Morphological differentiation among three Thelazia species (Nematoda: Thelaziidae) by scanning electron microscopy. Parasitol Res 2007; 101:145-151.

28. Araujo AC, Figueredo-Silva J, Souto-Padrón T, Dreyer G, Norões J, De Souza W. Scanning electron microscopy of adult Wuchereria bancrofti (Nematoda: Filarioidea). J Parasitol 1995; 81(3):468-474.

29. Aoki Y, Katamine D. Scanning electron microscopic observations on Dirofilaria immitis. Trop Medic 1975; 17:27-34.

30. Franz M, Zielke E. Scanning electron microscope study on larvae of Wuchereria bancrofti from the vector and from experimental rodent hosts. Tropenmed Parasitol 1980; 31:345-356.

31. Kozec WJ, Orihel TC. Ultrastructure of Loa loa microfilaria. Intern J Parasitol 1983; 13:19-43.

32. Adami YL, Oliveira AM, Lanfredi RM, Maia-Herzog M. First report on surface aspects of Mansonella ozzardi (Spirurida: Onchocercidae) microfilariae by scanning electron microscopy: preliminary results. Revista de patologia tropical 2018; 47:195-198.

33. Huang L, Appleton JA. Eosinophils in helminth infection: Defenders and dupes. Trends Parasitol 2016; 32(10):798-807.

34. Otranto D, Eberhard ML. Zoonotic helminths affecting the human eye. Parasit Vectors 2011; 4:41.

35. González-Miguel J, Rosario L, Rota-Nodari E, Morchón $\mathrm{R}$, Simón F. Identification of immunoreactive proteins of Dirofilaria immitis and D. repens recognized by sera from patients with pulmonary and subcutaneous dirofilariosis. Parasitol Int 2010; 59(2):248-256.

36. Giori L, Garbagnoli V, Venco L, Genchi M, Bazzocchi C, Bertazzolo W. What is your diagnosis? Fine-needle aspirate from a subcutaneous mass in a dog. Mixed neutrophilic-eosinophilic inflammation with Dirofilaria fragments. Vet Clin Pathol 2010; 39(2):255-256.

37. Haim A, Kitchen M, Auer H, Rettenbacher T, Schmuth M. A case of human Dirofilaria repens infection, causing an asymptomatic subcutaneous nodule. Parasitol Res 2020; 119(5),1703-1705.

38. da Silva RC, Langoni H. Dirofilariose: zoonose emergente negligenciada. Ciênc Rural 2009; 39(5): 1615-1624.

39. Maraghi S, Rahdar M, Akbari H, Radmanesh M, Saberi AA. Human dirofilariasis due to Dirofilaria repens in AhvazIran: A report of three cases. Pak J Med Sci 2006; 22:211213.

40. Fuentes I, Cascales A, Ros JM, Sansano C, Gonzalez Arribas JL, Alvar J. Human subcutaneous dirofilariasis caused by Dirofilaria repens in Ibiza, Spain. Am J Trop Med Hyg 1994; 51:401-404.

41. Genchi C, Kramer LH, Rivasi F. Dirofilarial infection in Europe. Vector Borne Zoonotic Dis 2011; 11(10):13071317. 